\title{
intuitio
}

Revista do PPG em Filosofia da PUCRS

http://dx.doi.org/10.15448/1983-4012.2019.1.29865

\section{OS SISTEMAS DA FILOSOFIA MODERNA ${ }^{1}$}

\author{
THE SYSTEMS OF MODERN PHILOSOPHY
}

Matheus Gomes Reis Pinto ${ }^{2}$

Resumo: A tradução que se segue diz respeito à primeira parte do texto de Antonio Rosmini-Serbati (1797-1855), intitulado Breve schizzo dei sistemi di Filosofia Moderna e del proprio sistema (publicado postumamente em 1913 e 1942), em que o autor apresenta sete filósofos que representam, segundo sua concepção, os sistemas filosóficos relevantes do período moderno, em especial do século XVIII. Contudo, ainda que o elenco de filósofos e seus sistemas apresentem uma aparente ordem cronológica, nota-se antes uma linha expositiva apoiada sob um desenvolvimento conceitual e sistemático, onde cada filósofo aqui exposto apresenta um progresso, do ponto de vista do autor, com relação a seus predecessores. Desse modo, o texto tem início por uma breve caracterização do pensamento de Locke, desenvolvendo-se em sistemas filosóficos como de Condillac, Berkeley, Hume, Reid, Kant, e, por fim, com a proposta filosófica de Fichte.

Palavras-chave: Filosofia moderna; Sistemas e métodos; Epistemologia.

\footnotetext{
N. do T.: Traduzido do original "I sistemi della filosofia moderna" de Antonio Rosmini-Serbati, esta tradução diz respeito à primeira da obra "Breve schizzo dei sistemi di filosofia moderna e del proprio sistema", cujos direitos autorais são de domínio público. Tradução feita como parte de um projeto de extensão realizado na Università di Bologna, em 2016, pela Universidade Federal do Rio Grande do Sul (UFRGS).

2 Universidade Federal do Rio Grande do Sul - UFRGS. ORCID: http://orcid.org/0000-0002$3123-6249$
} 


\begin{abstract}
The following translation concerns the first part of the work of Antonio Rosmini-Serbati (1797-1855), entitled Breve schizzo dei sistemi di Filosofia Modernae del proprio sistema (published posthumously in 1913 and 1942), in which the author presents seven philosophers representing the relevant philosophical systems of eighteenth century. Although the cast of philosophers and their systems seems to present a chronological order, it is possible to note an expository line supported under a conceptual and systematic development, where each philosopher here introduced presents a progressive development in relation to its predecessors. With that being said, the text begins with a brief characterization of Locke's philosophy, which develops in philosophical systems as such of Condillac, Berkeley, Hume, Reid, Kant, ending with the philosophical system of Fichte.
\end{abstract}

Keywords: Modern philosophy; Systems and methods; Epistemology.

\title{
Nota do tradutor
}

Antonio Rosmini-Serbati (1797-1855) foi um filósofo italiano que pretendeu, com sua filosofia, restabelecer a harmonia entre razão e religião, equilíbrio este dissolvido sobretudo em virtude da congregação religiosa presente no Iluminismo. Nesse sentido, o autor se dedica a uma tradição de philosophia perennis, que o leva a reler extensivamente obras filosóficas pós-renascentistas e desenvolver suas próprias visões sobre fundamentos da filosofia e suas aplicações. Rosmini descreve seu objetivo e método como comprometidos em combater o erro e sistematizar a verdade, com vistas a apresentar uma filosofia que sirva de base para os vários ramos do conhecimento. Segundo o autor, a tarefa negativa de combater o erro não é, no entanto, suficiente. É necessário além disso, diz Rosmini, produzir um "sistema de verdade", um sistema que demonstre claramente como a passagem dos princípios mais gerais e evidentes para níveis mais específicos de conhecimento ocorre. Em vista disso, o autor defende a liberdade de filosofar, e procura reconciliar, sempre que possível, visões aparentemente contrastantes, de modo que sua intenção é apresentar uma imagem do conhecimento como único, simples 
e indivisível, fazendo-se necessário, nesse sentido, uma investigação sobre os principais sistemas filosóficos de sua época.

Mais conhecido na Itália, Antonio Rosmini-Serbati teve sua formação acadêmica na Università di Padova, em 1816, onde recebeu o título de Doutor em Teologia e Direito canônico. Rosmini foi uma figura controversa durante sua vida, e para além dela. O filósofo, e também padre, acolheu o movimento nacionalista italiano, criticando sobretudo as tendências anticlericais e anti-católicas de sua época. Em consequência disso, Rosmini estreita relações com o Papa Pio IX, de sorte que o acompanha ao exílio após a eclosão da Revolução Romana. Em 1849, por sua vez, duas de suas obras reformistas eclesiásticas são postas no Index Librorum Prohibitorum, obrigando-o a retirar-se para a cidade de Stresa, onde vem a falecer em 1855. Um ano antes de sua morte, após novos ataque à sua obra, os escritos de Rosmini são retirados do Index e autorizados a serem lidos. Seu trabalho filosófico é centrado sobretudo nas noções de ser, dignidade humana, moralidade, objetividade do pensamento e certeza, direitos humanos, natureza da sociedade humana, e teologia natural.

\section{Os sistemas da Filosofia Moderna}

John Locke (1632-1704)

John Locke promove a dissolução do problema da origem das ideias. Segundo Locke, todas as ideias provêm de sensações e reflexões, de modo que, por reflexão, compreende o trabalho que a faculdade da alma humana exerce sobre as sensações. Ele nega, por conseguinte, que as ideias sejam inatas; e por ideias inatas, entende ser a cognição própria que o ser humano possui por natureza.

\section{Étienne Bonnot de Condillac (1714-1780)}

A filosofia de Locke difunde-se na França com Étienne Bonnot de Condillac, que, no entanto, posteriormente a modifica. Condillac reorga- 
niza o pensamento de Locke de modo a eliminar a reflexão de sua teoria, afirmando que a mesma deveria ser tomada como mera sensação. Nesse sentido, Condillac vangloria-se por simplificar a filosofia ao reduzir toda a cognição humana a sensações, reivindicando que o ser humano possui apenas uma faculdade, qual seja, a do sentir; e que as faculdades da memória, da imaginação, do intelecto, e da razão, seriam nada mais que modos de sentir. Este sistema trouxe notórias consequências à moralidade e à religião, uma vez que, não tendo o ser humano outra faculdade para além das sensíveis, o bem e o mal seriam considerados tão somente modos agradáveis ou dolorosos de sentir, onde caberia à moral obter para si as mais agradáveis sensações, evitando as desagradáveis Esse sistema imoral é desenvolvido na França por Claude-Adrien Helvétius (1715-1771), onde é posteriormente difundido na Inglaterra, à prosperidade pública, por Jeremy Bentham (1748-1832), o propagador do utilitarismo.

\section{George Berkeley (1685-1753)}

Berkeley foi um bispo anglicano de boa índole, educado na escola de Locke. Enquanto outros pensadores deduziam a partir do sistema sensitivo de Locke o materialismo, Berkeley compromete-se em extrair o espiritualismo de tal sistema do seguinte modo: admitindo como algo já provado e acolhido universalmente ao seu tempo que todo o conhecimento humano se reduz a um complexo de sensações, de modo que observa que as sensações só poderiam existir em seres sensíveis, sendo elas modificações dos mesmos; as sensações, portanto, não se encontrariam fora do ser humano, mas unicamente em seu interior, na alma humana. Se, contudo, o ser humano não conhecesse nada mais que sensações, os objetos de seu saber não estariam fora, mas dentro de sua própria alma como modificações do espírito. Assim, todo o mundo exterior não existiria senão em aparência; isso não quer dizer que de sensações na alma se manifestam modificações dela mesma. Esse sistema, que nega a exterioridade corpórea deixando intacto somente o espírito, chama-se 
idealismo. Berkeley aplica seu sistema à análise de corpos, enumerando todas as qualidades sensíveis de modo a definir cada uma delas como meras sensações. Nesse sentido, Berkeley conclui que tudo o que sabemos sobre corpos se reduz a uma combinação de sensações, e que, portanto, essas qualidades estariam em nós mesmos, e não fora, como ordinariamente se acreditara. Em seus famosos diálogos de Filonous e Filylas, Berkeley questiona de onde originam-se as sensações, respondendo do seguinte modo: da ação imediata que exerce Deus em nosso espírito. Demonstra-se, com o exemplo dos sonhos, que não é necessário que tenhamos presentes os objetos corpóreos, uma vez que a convicção de sua presença é obtida em razão de termos tais sentimentos. Assim, a vida humana, no sistema de Berkeley, não seria outro que um sonho contínuo, e entre a vida e os sonhos haveria somente uma diferença: na vida, as sensações de vários sentidos vinculam-se de maneira harmônica e constante, enquanto que nos sonhos, essa relação pode ser desarmônica e inconstante, de modo que as sensações ou imagens visuais não possuiriam correspondência com as do tato, por exemplo.

\section{David Hume (1711-1776)}

Hume também foi educado a partir da filosofia lockeana, admitindo como certo e sem necessidade de exame o princípio que toda a cognição humana se reduz às sensações. Ora, se por um lado Berkeley deriva o idealismo desse princípio, do mesmo modo Hume deriva o ceticismo, isto é, o sistema daqueles que negam toda e qualquer certeza a respeito da cognição humana. Nesse sentido, Hume deduz que o raciocínio do ser humano apoia-se sobre o princípio de causa, exposto do seguinte modo: se há um efeito, há um causa. Porém, esse princípio é falso e ilusório, pois a causa jamais pode ser uma sensação - e caso seja, deve ser uma entidade ativa. Ora, as sensações não são entidades, mas a modificação de entidades: não é ativa, e sim passiva; por conseguinte, as sensações jamais poderiam ser a causa. No entanto, o ser humano não conhece nada 
além das sensações, de modo que jamais conheceria as causas: conhece sensações precedentes e sucedentes, mas raciocina falsamente quando acredita que o que precede deve ser a causa do que sucede, sendo falso o argumento: hoc post hoc, ergo propter hoc. Logo, sempre que o ser humano fala de entidades que supõem causas no mundo sensível, presume fazer o impossível, uma vez ser não se pode chegar, a partir das sensações, ao conhecimento de qualquer causa. Esse sistema é manifestamente ímpio, pois, negando a causa, ou colocando-a em dúvida, nega-se também, ou põe-se em dúvida, a existência da causa primeira, Deus.

\section{Thomas Reid (1710-1796)}

O escocês Reid espanta-se com as terríveis consequências deduzidas do sistema de Locke, e com as duas fortes concepções de Berkeley e Hume. Essas consequências, que de certo modo aniquilam o mundo exterior e a certeza da cognição humana, são deduzidas com tanto rigor lógico que, concedidas as premissas, não poderia-se refutá-las. Por outro lado, essas consequências se opõem ao senso comum dos seres humanos, destruindo a moralidade e a religião, não podendo, assim, serem verdadeiras. Reid conclui que o erro está nas premissas, e que não se deve aceitar cegamente o sistema de Locke, mas sim submetê-lo novamente a um profundo exame a fim de encontrar o pecado oculto. Neste empreendimento realizado com toda força de sua inteligência, Reid finalmente acredita ter encontrado uma resposta. Ele nota que as percepções humanas não permanecem nas simples sensações. Se é verdade que o ser humano não conhece nada além das sensações, não poderíamos afirmar somente isso. A experiência diz que os seres reais não são estritamente sensações: Reid não acredita conhecer apenas as modificações de seu próprio espírito, mas acredita conhecer as diferentes substâncias em si que exercem ações sobre ele. Convém, portanto, dizer que não possuímos somente a faculdade do sentir, mas também uma outra faculdade misteriosa que, no caso das sensações, impõe uma existência para além delas. Mas, de que modo podemos explicar 
uma faculdade que afirma algo que não está nos sentidos? Onde habita o objeto desta faculdade? E quem possui tal espírito de percepção? São essas as questões que propõe Reid, e que contêm o nó de sua demanda ideológica. O filósofo escocês responde do seguinte modo: não devemos nos distanciar dos fatos, pois é um fato que o espírito humano percebe a substância e a entidade, coisas essas que não caem sob os sentidos, que são muito diferentes das sensações, mas que, todavia, percebemos em razão delas. Por isso, deve-se dizer que o espírito humano possui em sua própria natureza um instinto que o carrega. Esse instinto é reconhecido como uma faculdade primitiva que não admite razões ulteriores. Reid apresenta, portanto, uma proposta de natureza em que o ser humano seria obrigado, quando recebesse sensações, a não permanecer nelas, mas de transpassá-las, com o ato de seu pensamento, à certeza de que há outras entidades reais chamadas corpos, que seriam causas das próprias sensações.

Mediante essa faculdade primitiva, que afirma ou percebe a mesma substância corpórea, Reid considera refutar o idealismo de Berkeley ao assegura a existência dos corpos, bem como acredita refutar o ceticismo de Hume ao colocar o critério de certeza sob a faculdade primitiva da natureza humana. Reid orgulha-se, assim, de reconciliar a filosofia ao senso comum do gênero humano do qual os filósofos ingleses precedentes haviam desviado. O mérito da escola escocesa é o de realizar as primeiras tentativas de distanciamento da filosofia e do sistema sensitivo de Locke e Condillac. Enquanto a escola escocesa parece instaurar finalmente as bases sólidas do saber filosófico, surge o sofista de Königsberg para derrubá-las novamente, e com maior vigor.

\section{Immanuel Kant (1724-1804)}

Kant se apropria da palavra do filósofo escocês, Thomas Reid, e grosso modo argumenta o seguinte: é correto afirmar que a certeza que o ser humano tem sobre a existência dos corpos não provém das sensações, mas de uma faculdade totalmente diversa da sua própria natureza, em 
que ela própria (a natureza do espírito humano) nos obriga a admitir os corpos no instante em que nossa sensibilidade recebe sensações. Ora, se esse for o caso, a fé que temos sobre a existência dos corpos seria um efeito da natureza do nosso espírito. Portanto, se o nosso espírito possuísse uma forma diferente, ele não seria necessário para afirmar a existência dos corpos. Logo, a veracidade da existência dos corpos seria subjetiva, isto é, em relação ao espírito que a pronuncia, não sendo, com efeito, objetiva; isto significa dizer que, se existem corpos, somos obrigados a admiti-los, uma vez que, assim informados, não poderíamos resistir ao instinto que nos conduz à natureza; no entanto, disso não se segue que os corpos existam em si mesmos, que possuem uma existência objetiva independente de nós. Kant expande essa ideia à toda cognição humana, afirmando que, sendo tudo ato e produção do espírito, no qual não pode ausentar-se de si, não poderíamos ter outra verdade ou certeza que não subjetiva, e que, portanto, o espírito jamais poderia ter certeza que as coisas são como aparecem. Kant observa que todas as entidades agem segundo leis de sua própria natureza, e que a produção dessas entidades detém a marca de tais leis. Se, portanto, as cognições são produtos do espírito humano, mesmo essas devem ser respeitadas de acordo com a natureza e as leis desse espírito. E, quem sabe, questiona Kant, se houvesse um outro espírito diversamente construído do nosso, não veríamos as coisas muito diferentes daquelas que aparecem a nós? Kant oferece o exemplo de um espelho cuja imagem modifica-se em virtude da forma das coisas que nele refletem, de modo que um espelho côncavo, a título de exemplo, faz com que todos os objetos se alonguem, e em um espelho convexo, diminuam.

O espírito humano, portanto, da suas próprias formas aos objetos de sua cognição, não recebe as formas dos objetos em si. Ora, o ofício do filósofo consiste em elucidar quais são essas formas, enumerando-as uma a uma e descrevendo cada qual com suas próprias determinações. Em razão disso, não se faz necessário observar todos os objetos do conhecimento humano, transportando as formas desses objetos ao espírito; assim, elimina-se a ilusão 
transcendental que diz respeito aos seres humanos acreditarem que tais formas são dos objetos, quando na verdade são do próprio espírito. Kant ocupa-se dessa investigação em sua obra intitulada Crítica da Razão Pura (1781 e 1787), e conduz o trabalho do seguinte modo:

O autor diz que há duas formas sensíveis: uma no sentido externo, que se chama espaço, e outra no sentido interno, que se chama tempo; diz, também, que há quatro formas do intelecto, a quantidade, a qualidade, o modo e a relação; e diz, finalmente, que há três formas da razão, a matéria absoluta, o todo absoluto, e o espírito absoluto; ou seja, a matéria, o mundo e Deus. Kant, portanto, pretende combinar os mais opostos sistemas concebidos pelos filósofos, dividindo-os em duas grandes classes: os dogmáticos e os céticos. Os dogmáticos são aqueles que admitem a verdade e certeza da cognição humana; os céticos, aqueles que negam toda a verdade e a certeza. Kant diz que ambos estão corretos: têm razão os dogmáticos, pois há uma verdade e uma certeza, embora subjetiva, ou seja, relativa ao ser humano sujeito; e têm razão os céticos, pois não há uma verdade e uma certeza objetiva, isto é, dos objetos considerados em si mesmos, não podendo o ser humano conhecer coisa alguma como algo em si mesmo. Este sistema designa-se crítico, uma vez que faz crítica aos outros sistemas e à razão humana; e denomina-se transcendental, pois transcende os sentidos e a experiência, submetendo à crítica tudo aquilo que o ser humano pensa conhecer para além do mundo sensível; mas, de fato, o sistema kantiano é:

1) Cético: pois a verdade e a certeza subjetiva que admite não são verdades e nem certezas senão por abuso de palavras.

2) Idealista: pois, não admitindo a existência de corpos, que subjetivamente são produções do instinto e das formas inatas do espírito humano, não os admite senão em aparência, negando-lhes, também, uma existência própria. Além disso, seu sistema é o idealismo movido do particular para o geral - aquele que Berkeley aplicara apenas aos corpos, e Hume a 
todos os objetos da cognição humana, fossem eles corpóreos ou espirituais, concretos ou abstratos.

3) Ateísta: pois, se a razão humana não pode assegurar a verdade absoluta e objetiva dos objetos que se apresentam, não resta a possibilidade de conhecer com certeza a existência de Deus, tornando-o também uma aparência subjetiva; é um sistema ateísta, também, pois Kant próprio o diz ser, criticando todos os argumentos percorridos pelos filósofos que tentaram provar a existência divina, demonstrando serem todos ineficazes e inúteis.

4) Panteísta: pois, neste sistema, não restando nada a não ser o espírito, que em virtude de seus instintos e de suas formas produz e expõe consigo tudo o que há, segue-se que não existe nada senão uma substância, o próprio sujeito humano, que traz consigo tudo, do universo ao próprio Deus; Deus torna-se, portanto, em tal sistema, uma modificação do ser humano.

5) Espiritualista, e por um período de tempo materialista: pois, aquilo que é dito matéria é, no objeto humano, como que um produto seu; e aquilo que é dito espírito está, também no objeto humano, como que produzindo e modificando a si mesmo, em que o espírito humano vem a ser, por instantes, espírito e matéria.

\section{Johann Gottlieb Fichte (1762-1814)}

Fichte foi discípulo de Kant, e, ao publicar sua obra intitulada Fundação de toda a doutrina da ciência (1794-95), acreditou ter dado uma explicação científica ao sistema kantiano. Kant, no entanto, não identifica em sua exposição o seu sistema, fazendo com que Fichte perceba ter criado um novo.

A diferença entre a filosofia Crítica e o Idealismo Transcendental essa segunda denominação mantida pelo sistema de Fichte - consiste em Kant dizer que o ser humano, não podendo ele saber se os objetos 
que lhes aparecem são tais como aparecem, não excluiria a possibilidade de serem tais, uma vez que poderiam existir independente de nós, ainda que não fosse possível ter certeza disso. Fichte nega determinadamente essa possibilidade afirmando que os objetos não podem ser outro que produções do ser humano próprio, argumentando o seguinte: todos os objetos do conhecimento são produções do ato de conhecer; mas o ato de conhecimento é uma produção do espírito humano, assim sendo, também, os objetos. No entanto, esses objetos são o mundo, Deus e o ser humano; e desse modo, essas três coisas nada mais são que produções que o espírito representa antes em si como objetos de seu conhecimento. Fichte ocupa-se, portanto, em explicar como o espírito humano produz, a partir de si mesmo, todas as coisas. O autor diz que, com o primeiro pronunciado, com a primeira criação, o eu introduz a si mesmo. Antes do ser humano pronunciar o eu, ele ainda não estaria na forma do eu; e, com o segundo pronunciado, que é uma segunda criação, o ser humano introduz o não-eu. O não-eu é, para Fichte, tudo o que não é o eu, e assim, portanto, também o mundo exterior, as divindades e qualquer objeto do pensamento humano. Ora, esses dois atos no qual o espírito introduz o eu e o não-eu são correlativos, de modo que um não poderia existir sem o outro. Não pode o eu pronunciar a si mesmo senão em contraposição a algo diferente de si, onde a contraposição nega a si mesmo, diferenciando-se de todo o resto. Não se pode pronunciar o não-eu, se ao não-eu não se contrapõe o eu, e, portanto, não se distingue de si mesmo. Fichte estabelece, assim, uma primeira operação do espírito, também chamada de intuição, que possui duas relações, ou termos, que se negam reciprocamente. Com essa primeira operação misteriosa, Fichte pretende explicar não somente a origem da cognição humana, mas a existência de todas as coisas.

Restringindo-se sob a denominação de que o não-eu é tudo o que não é o eu, o não-eu abrange tanto Deus quanto o mundo. Logo, chega-se à absurda proposição de que o mundo não é somente uma criação humana, mas uma criação do homem e do próprio Deus. Este sistema chama-se 
Idealismo Transcendental, pois aplica o princípio idealista de Berkeley a tudo o que há, obtendo através de uma lógica inexorável todas as consequências, e assim deparando-se com o abismo; Fichte ainda declara não permanecer mais a dúvida que fora mantida na filosofia crítica de Kant não, porém, se as coisas tiverem uma subsistência própria. O autor retorna, por conseguinte, ao ceticismo dogmático, o ceticismo crítico de Kant.

A partir do sistema de Fichte, surge na Alemanha outros dois sistemas, o de Schelling e de Hegel: o primeiro, o sistema da Identidade Absoluta, e o segundo, o sistema da Ideia Absoluta. A exposição desses sistemas é aqui omitida, não se afigurando necessária para o entendimento daquilo que vim expondo, sendo apenas esse o propósito do texto ora apresentado.

\section{Referências:}

CORMACK, G.; HICKEY, D. Rosmini and Rosminianism. In: THE CATHOLIC Encyclopedia. New York: Robert Appleton Company, 1912. v. 13.

HUGH, C. (ed.). Encyclopedia Britannica. Cambridge: Cambridge University Press, 1911. v. 23. p. 738-739.

MASSIMO, C. Dizionario Biografico degli Italiani. Roma: Treccani, 1999.

ROSMINI-SERBATI, A. Breve schizzo dei sistemi di filosofia moderna e del proprio sistema. Introduzione e commento di Silvio Ferrighi. Milano: Carlo Signorelli Editore, 1942. 